\title{
CORRECTION
}

\section{Correction to: Expression of COX-2 and Nrf2/GPx3 in the anterior vaginal wall tissues of women with pelvic organ prolapse}

\author{
Te Lin ${ }^{1} \cdot$ - Yuting $\mathrm{Ji}^{1} \cdot$ Ying Zhao ${ }^{1}$ Zhijun Xia ${ }^{1}$ (D)
}

Published online: 1 December 2021

๑) Springer-Verlag GmbH Germany, part of Springer Nature 2021

\section{Correction to: \\ Archives of Gynecology and Obstetrics \\ (2021) 303:1245-1253 \\ https://doi.org/10.1007/s00404-020-05913-8}

In the original article, the Figure 3 is published incorrectly.

The correct Fig. 3 is given below:

The original article has been corrected.

The original article can be found online at https://doi.org/10.1007/ s00404-020-05913-8.

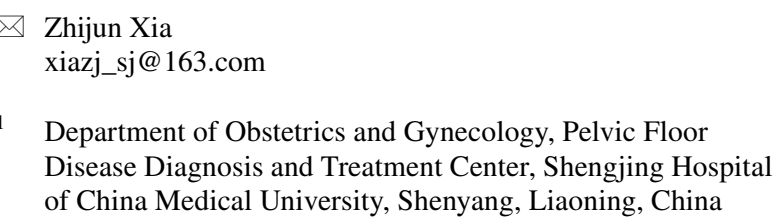


PGE2
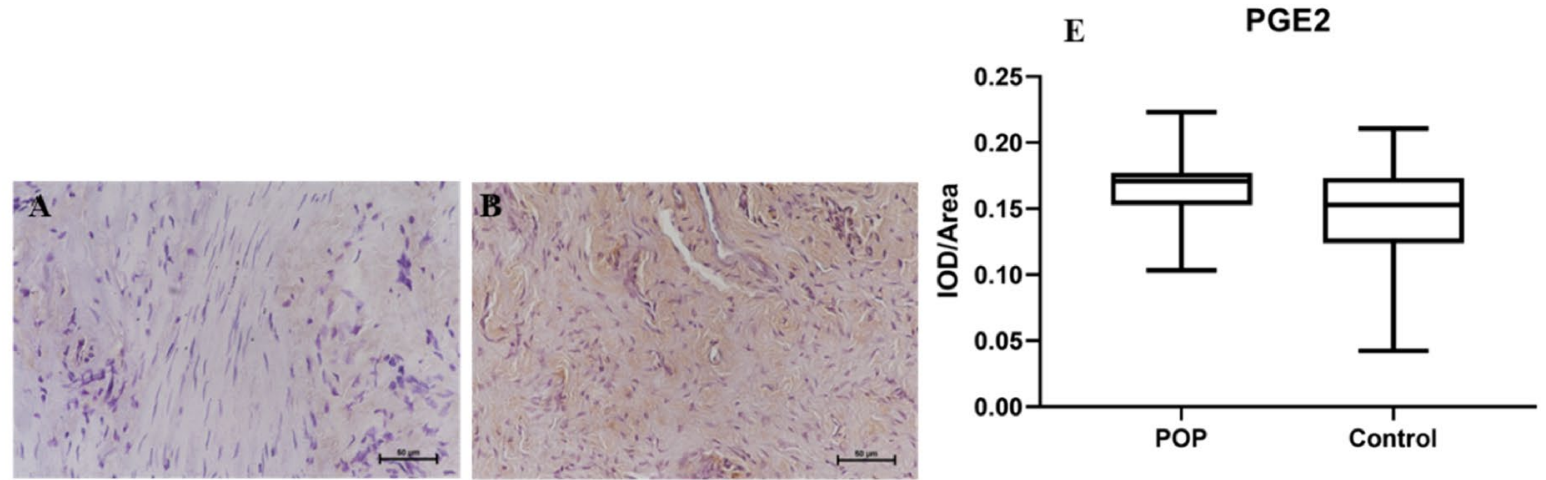

COX-2
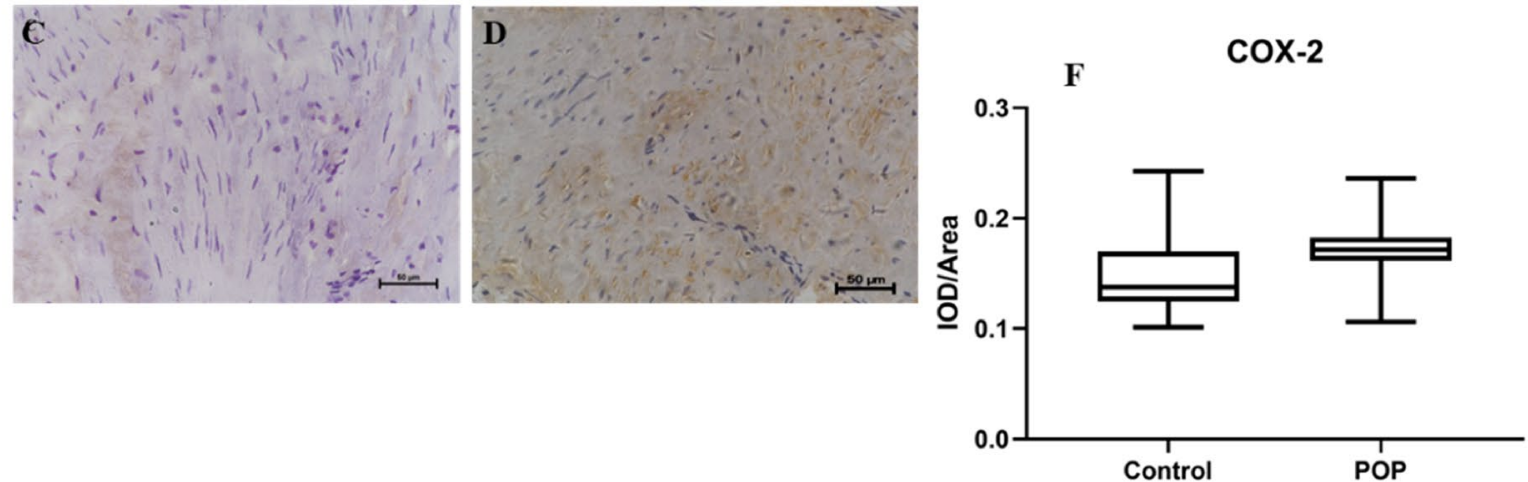

Fig. 3 IHC for COX-2 and PGE2 in the anterior vaginal wall $(\times 400)$. a For PGE2 expression in control group (median $=0.15$ ), $\mathbf{b}$ for PGE2 expression in POP group (median $=0.17$ ), $\mathbf{c}$ for $\mathrm{COX}-2$ expression in

control group (median $=0.14), \mathbf{d}$ for $\mathrm{COX}-2$ expression in POP group (median $=0.17$ ). e, f IOD/area for quantitative analysis (Mann Whitney $U$ test). $P<0.05$

Publisher's Note Springer Nature remains neutral with regard to jurisdictional claims in published maps and institutional affiliations. 